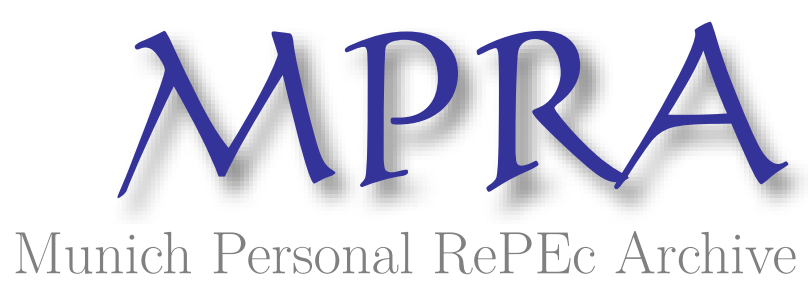

\title{
Immigration policy and birth weight: positive externalities in Italian law
}

Pieroni, Luca and Salmasi, Luca

University of Perugia, University of Perugia

1 October 2013

Online at https://mpra.ub.uni-muenchen.de/50368/

MPRA Paper No. 50368, posted 04 Oct 2013 05:52 UTC 


\title{
Immigration policy and birth weight: positive externalities in Italian law
}

\author{
Pieroni L. ${ }^{a}$ and Salmasi L. ${ }^{a}$ \\ ${ }^{a}$ Department of Economics, Statistics and Finance, University of Perugia \\ ${ }^{b}$ Department of Medical and Surgery Specialities and Public Health, Division of Public Health, University of Perugia
}

\begin{abstract}
A decade ago, the political party of the Italian center-right voted a law restricting immigration. It emphasized severity in granting permits to stay and limited illegal immigration. However, the law became effective in early 2005, when the Italian parliament approved the decree for its application. Only one article of this law, granting amnesty for illegal immigrant workers, was immediately effective, and gave irregular immigrants the opportunity to regularize their status. As a result, 650,000 immigrants were granted the status of foreign nationals in Italy.

In this paper, we examine whether the increase in the prevalence of "regular immigrants" has led to an improvement in health outcomes of babies born to migrant women, measured in terms of birth weight. Two hitherto unexploited birth sample surveys published by Italian Institute of Statistics in 2002 and 2005 were used for this study. The surveys, concern interviews with 100,000 mothers who delivered a child between July 2000 and June 2001 in the first survey and in 2003 in the second survey. Our estimates show that regular immigration reduced the probability of low birth weight, indicating that economic benefits in place at birth may be strengthened by increased future productivity.

Keywords: birth-weight, immigrants regularization, propensity score matching, difference-in-differences

JEL classification: I10, I12, I18
\end{abstract}




\section{Introduction}

The rise of the new Italian center-right government in 2001 had important repercussions on migration policy and led to new legislation which was approved in July 2002 (Law 189/2002). This law had as its goals better management of migration flows and more effective prevention of illegal immigration, and it came into force when the Italian parliament approved its implementation in early 2005. Although the initial intentions were quite different, this law allowed irregular immigrants working in domestic service and as carers to be regularized, a situation extended two months later also to workers in industry. A short-term effect of the law was that 705,000 irregular immigrants were made eligible for regularization and, of these, 650,000 were approved.

This study examines the unintended effects on the birth weight of babies of immigrant mothers who changed their status from irregular to regular in 2002. As generally proposed in this literature, we use low birth weight (LBW) as a health outcome indicator. LBW is defined by the World Health Organization as weight at birth of less than 2,500 grams. This measure has been widely studied in the economic literature because it has also been found to affect welfare costs significantly (Abrevaya \& Dahl 2008). Almond et al. (2005), using data referring to newborns in a sample from the states of New York and New Jersey, estimate that a representative newborn weighing 2,000 grams gives rise to a direct hospital cost of 15,000 dollars in the United States. In addition, cuts in LBW have the potential to produce benefits for health, in terms of individual physiological and cognitive development over a longer time-span (Heckman 2000).

Our working hypothesis is that the 2002 Italian law on immigration reduced immigrants' socio-economic vulnerability and fostered fertility choices. Linked with the health outcomes of pregnant mothers, the regularization process is assumed to promote better use of prenatal care services by immigrant mothers. As shown by Geraci et al. (2010), irregular immigrants have a lower number of prenatal examinations and make their first visit later than regular or Italian-born mothers, mainly because they are afraid of being reported to the authorities ${ }^{1}$. However, inadequate access to prenatal care in Italy has been found to be statistically associated with higher probability of LBW (Chiavarini et al. (2012) and Bacci et al. (2012)). As shown by the Italian Institute of Statistics (ISTAT) in

\footnotetext{
${ }^{1}$ For a discussion of this point, see Amuedo-Dorantes \& Mundra (2005).
} 
2003-2004, around $80 \%$ of total population growth was due to immigrants. In addition, if we look at official data from ISTAT (2001, 2002, 2003), between 2001 and 2003 babies born to foreign mothers increased by almost $20 \%$.

Our empirical strategy compares what happened in terms of LBW in a treatment group of immigrant mothers with respect to a control group. A fundamental challenge to this approach is to determine counterfactual outcomes. When newborns' birth weight in the group of immigrant women is observed, after the opportunity granted to illegal immigrants to regularize their status, the impact of the law should be assessed in relation to the potential outcomes in the absence of regularization inflows. This counterfactual outcome is approximated by observed birth weight in the selected groups of foreignborn mothers with Italian nationality and Italian mothers, which are not affected by the (unintended) effects of the immigration law.

The main criticism of this approach is that treatment and comparison groups may differ in terms of unobservable and observable characteristics. The economic and medical literature - focusing on migrant women's fertility decisions or newborns' health status in industrialized countries - showed that there is a large gap, in terms of newborns' health, between immigrant and Italian-born mothers ${ }^{2}$. This gap is due to the fact that, although it is generally true that individuals who decide to migrate are healthy they also usually belong to the lower part of the welfare distribution in their countries of origin, since those who are highly skilled or richer have fewer incentives to migrate. Thus, a mixed (unobserved) effect may arise (see Borjas (1990), Hildebrandt \& McKenzie (2005)): on one hand, immigrant mothers have an advantage because of their better physical condition; on the other hand, they also present negative outcomes, since they usually migrate from countries with high inequality levels, so that low-skilled individuals are more likely to migrate. A simple comparison between Italian and immigrant mothers will thus fail to estimate the true difference in terms of birth weight.

We deal with this econometric issue using a difference-in-differences (DD) model combined with a propensity score matching (PSM) estimator, and use the propensity score difference-in-differences (PSDD) model to estimate the effects of the cited massive regularization on birth weight. The combination of these two methods allows us to account for

\footnotetext{
${ }^{2}$ Urquia et al. (2010) in their recent review of this literature suggest that different sources of heterogeneity have a role to play in determining positive, negative or non-significant outcomes at birth.
} 
time-invariant unobservable characteristics, which differ between treatment and control groups, comparing only those mothers with the most similar observable characteristics. We also take into account the concern that ordinary least square standard errors for the DD estimator may not be accurate in the presence of correlations between outcomes within groups and between time periods. This problem has been specifically analyzed for the case with two groups and two time periods by Donald \& Lang (2007), Bertrand et al. (2004). Here, we use the two-step estimator proposed by Donald \& Lang (2007), as the most appropriate method to obtain consistent standard errors in estimating treatment effects.

The contribution of this paper lies in the datasets and the opportunities it offers for econometric identification of immigration law effects. We use data from the Birth Sample Survey (BSS) conducted by ISTAT in 2002 and 2005, concerning interviews with 100,000 mothers between July 2000 and June 2001 in the first survey (wave 1 ), and in 2003, in the second survey $\left(w_{a v e}\right)$. The years in which the surveys were conducted are precisely those before and after the immigration law came into force and, thanks to this feature, we can adopt a quasi-experimental approach to estimate the effect of regularization on the probability of LBW.

Although we cannot distinguish between eligible and non-eligible immigrants, we propose a robustness analysis to test whether the estimated effect varies when we consider various groups of babies born to mothers with different employment status. As Art. 33 of Law 189/2002 covers regularizations linked with employment status and duration, we may suspect that estimates differ significantly, according to the heterogeneous employment status of parents. Thus, we estimate the effect of regularization on the probability of LBW in subgroups of newborns in which, at least, one parent was employed. Our results are in line with the expectation that leaving the status of illegal migrant has significant benefits in reducing the disparities between newborns of migrant mothers with respect to those unaffected by regularization, irrespective of whether this effect is caused directly by the mother or indirectly by the father.

The rest of the paper is organized as follows. Section 2 discusses the 189/2002 Italian law and its application to immigrant regularization. Section 3 describes the data and our empirical strategy. Section 4 presents the main results, and Section 5 concludes. 


\section{Immigration issues: the 189/2002 Italian law}

Law 189/2002 is composed of a set of rules aiming to regulate the flow of migrants into Italy to combat irregular immigration. Also regular immigrants are subjected to more restrictive rules linking permits to stay with work contracts, and making procedures for renewals more expensive.

The law was passed in response to problems of public order. At least in the developed countries of Western Europe, immigration is a public security issue and is often associated with increased criminal activities. This process became even more restrictive after the September 2001 terrorist attacks in the United States. These motivations were emphasized from the fact that the economic benefits of immigration in Italy were found to be relatively small in aggregate ${ }^{3}$.

Despite the intention of tightening immigration regulations in Italy, only the regularization norm (i.e., Art. 33 of Law 189/2002) became immediately effective after its official publication in July 2002. Thus, during this two-and-a-half-year period, the regularization was the most far-reaching measure used to reveal illegal foreign workers and to increase the number of regular immigrants.

\subsection{Eligibility to transit from illegal to legal immigrant status and the unin- tended effects of regularization}

The regularization of illegal immigrants promoted by Law 189/2002 was the most important one introduced in a European country, equalled later by the 2005 regularization in Spain. In Italy, more than 705,000 applications were presented and nearly 650,000 were accepted (approximately 92 per cent), although over 60,000 of these were conditional (Carfagna et al. 2008). The regularization of domestic workers and personal assistants (carers) was later also extended to other employees under Legislative Decree 195/2002, converted into Law 222/2002. Formally, employers' declarations had to be sent to the Italian Institute of Social Security (INPS), together with payment of 700 euros to cover welfare costs for the three months before the amnesty, as well as other administrative costs. Thanks to improved organization, operations were significantly faster compared with similar procedures carried out previously, despite the far higher number of applica-

\footnotetext{
${ }^{3}$ Hildebrandt \& McKenzie (2005), investigating Mexican immigrant workers, showed the existence of substitution effects with respect to comparable native groups.
} 
tions (see Table 1). The huge numbers of people applying for regularization were even more remarkable when we consider the relatively restrictive eligibility requirements compared with previous measures. In fact, only those working in families or employed in companies were able to apply, while self-employed, unemployed, and family members were excluded.

Clearly, this regularization, as well as those of the 1990s, had as one of its short-term effects a marked fall in irregular migration. For each legislative intervention, Table 1 lists the number of applicants, percentage of accepted applications, and gender differences about number of applications. The first intervention adopted was the so-called Martelli Law (Law 39/1990) which aimed at reducing the numbers of illegal immigrants. This trend continued in the two subsequent regularizations and culminated with the Law 189/2002. In early 2000, the number of illegal immigrants in Italy was much larger than that recorded before the amnesties in 1995 and $1998^{4}$. As the only possible beneficiaries were employees, a comparison with the number of permits to stay for employees in early $2002(623,000)$ gives us an even better idea of the extent of this regularization, after which the number of regularly employed foreign workers virtually doubled (Bonifazi et al. 2009).

Inspection of the official data (Table 1) reveals some salient features of the evolution over time of immigration in Italy. Regularizations until the end of the 1990s had in common a strong gender imbalance: the number of regularized women in the first three amnesties was around 30\%, whereas after the regularization of Law 189/2002, women accounted for almost $46 \%$ of applicants. This increase in the proportion of women among regularized immigrants was the result of greater migration from countries which in any case had a significant prevalence of women (Romania, Ukraine, Moldavia, Poland and Ecuador). The increase in demand for domestic help and carers, during the positive business cycle of the Italian economy, substantially increased women's immigration from the Balkans and Eastern Europe. This fact is even more evident from the number of applications made in 2002 by immigrant women from countries of the former Soviet Union: 383,000 permits to stay were issued, nearly $60 \%$ of the total amount, almost doubling the numbers of those already legally residing in Italy from the same area.

The exogenous variation in permits to stay not only represents an opportunity for

\footnotetext{
${ }^{4}$ In 2002 , there were 52 regularized immigrants for every 100 from countries with strong migratory pressure legally present.
} 
Table 1: Programs to grant immigrants regular status in Italy

\begin{tabular}{lcccc}
\hline \hline & $\begin{array}{c}\text { Law } \\
\mathbf{3 9 / 1 9 9 0}\end{array}$ & $\begin{array}{c}\text { Decree of Law } \\
\mathbf{4 8 9 / 1 9 9 5}\end{array}$ & $\begin{array}{c}\text { Decree of Law } \\
\mathbf{1 6 / 1 0 / 1 9 9 8}\end{array}$ & $\begin{array}{c}\text { Laws 189 } \\
\text { and 222/2002 }\end{array}$ \\
\hline Year & 1990 & $1995-96$ & 1998 & 2002 \\
N. of application & 235 & 256 & 251 & 705 \\
\% of accepted applications & 93.8 & 96.2 & 86.8 & 90.5 \\
\% of women & 26.0 & 31.0 & 28.9 & 45.8 \\
\hline \hline
\end{tabular}

Source: Bonifazi et al. (2009), from Italian Ministry of the Internal Affairs and Ministry of Labour.

evaluating the effect of immigration on some outcomes (in terms of newborns' health), it also can describe the labor market demand in a medium-term perspective. Although the annual renewal of permits depended on the existence of an employment contract, among foreigners who obtained permits in 2003, it should be noticed that more than $78 \%$ still had valid permits to stay in early 2007 (Carfagna et al. 2008). Thus, the (unintended) effects of regularization programs according to Italian law has not been repeatedly to regularize the same individuals who had returned to a state of illegality, but effectively to initiate a course of legality for most formerly illegal immigrants.

\section{$3 \quad$ Data and empirical strategy}

\subsection{Data}

The dataset used in this study is the Birth Sample Survey (BSS) published by the Italian Institute of Statistics (ISTAT) in $2002\left(w_{a v e}\right)$ and 2005 (wave $)_{2}$. This dataset collects information about babies born to about 50,000 women each year. The main information collected regards mother's and father's socio-demographic characteristics and the newborn's health status. The $B S S$ also collects information for a representative sample of foreign-born mothers - with or without Italian nationality - whose fertility choices are of particular interest for the aims of the present study. Table 2 shows descriptive statistics for the variables of interest in our analysis by mother's nationality: mother's and father's age, years of residence in Italy (if foreign-born), employment, marital status, education, and wealth. Clearly the group of foreign-born mothers differs in terms of observable characteristics from those of foreign-born mothers with acquired Italian nationality and Italian mothers, especially according to age, occupational status, and wealth (measured by a set 
of dummy variables which evaluate whether the accommodation where the respondent lives is owned or rented and by the number of rooms in it). However, we do not find any evidence of significant differences in sample composition between the two waves for each group analysed.

Table 2: Descriptive statistics

\begin{tabular}{|c|c|c|c|c|c|c|}
\hline \multirow[b]{2}{*}{ Variable } & \multicolumn{2}{|c|}{$\begin{array}{l}\text { Mothers born } \\
\text { outside Italy }\end{array}$} & \multicolumn{2}{|c|}{$\begin{array}{l}\text { Mothers born } \\
\text { outside Italy } \\
\text { (but with acquired } \\
\text { Italian nationality) }\end{array}$} & \multicolumn{2}{|c|}{ Italian mothers } \\
\hline & Wave $_{1}$ & Wave $_{2}$ & Wave $_{1}$ & Wave $_{2}$ & Wave $_{1}$ & Wave $_{2}$ \\
\hline$\%$ of low birth weight & 0.07 & 0.06 & 0.05 & 0.05 & 0.05 & 0.05 \\
\hline Mother's age: $\leq 24$ & 0.31 & 0.33 & 0.14 & 0.13 & 0.15 & 0.14 \\
\hline Mother's age: 25-29 & 0.27 & 0.29 & 0.32 & 0.26 & 0.28 & 0.27 \\
\hline Mother's age: $30-34$ & 0.24 & 0.22 & 0.32 & 0.33 & 0.32 & 0.31 \\
\hline Mother's age: $30-34$ & 0.12 & 0.1 & 0.16 & 0.2 & 0.17 & 0.19 \\
\hline Mother's age: $\geq 40$ & 0.07 & 0.06 & 0.06 & 0.07 & 0.08 & 0.09 \\
\hline Mother's years of residence: $0-7$ & 0.51 & 0.54 & 0 & 0 & 0 & 0 \\
\hline Mother's years of residence: 8-14 & 0.32 & 0.3 & 0 & 0 & 0 & 0 \\
\hline Mother's years of residence: $\geq 15$ & 0.16 & 0.15 & 0 & 0 & 0 & 0 \\
\hline Mother unemployed & 0.69 & 0.67 & 0.56 & 0.54 & 0.47 & 0.42 \\
\hline Mother employed & 0.31 & 0.33 & 0.44 & 0.46 & 0.53 & 0.58 \\
\hline Mother married & 0.13 & 0.2 & 0.08 & 0.09 & 0.07 & 0.1 \\
\hline Mother not married & 0.87 & 0.8 & 0.92 & 0.91 & 0.93 & 0.9 \\
\hline Mother's education: degree & 0.21 & 0.19 & 0.14 & 0.17 & 0.15 & 0.18 \\
\hline Mother's education: secondary school & 0.5 & 0.55 & 0.56 & 0.53 & 0.51 & 0.52 \\
\hline Mother's education: primary school & 0.3 & 0.25 & 0.3 & 0.3 & 0.34 & 0.29 \\
\hline Parity: 0 & 0.44 & 0.49 & 0.39 & 0.36 & 0.43 & 0.44 \\
\hline Parity: $1+$ & 0.56 & 0.51 & 0.61 & 0.64 & 0.57 & 0.56 \\
\hline Previous children born dead & 0.02 & 0.01 & 0.01 & 0.01 & 0.01 & 0.01 \\
\hline Previous abortions/miscarriages & 0.19 & 0.15 & 0.19 & 0.19 & 0.17 & 0.17 \\
\hline Father born in Italy & 0.66 & 0.67 & 0.91 & 0.91 & 0.97 & 0.97 \\
\hline Father born outside Italy & 0.34 & 0.33 & 0.09 & 0.09 & 0.03 & 0.03 \\
\hline Father's age: $\leq 24$ & 0.03 & 0.05 & 0.04 & 0.03 & 0.05 & 0.05 \\
\hline Father's age: $\overline{25}-29$ & 0.13 & 0.13 & 0.16 & 0.13 & 0.17 & 0.16 \\
\hline Father's age: $30-34$ & 0.31 & 0.26 & 0.35 & 0.32 & 0.34 & 0.33 \\
\hline Father's age: $30-34$ & 0.27 & 0.28 & 0.27 & 0.31 & 0.27 & 0.29 \\
\hline Father's age: $\geq 40$ & 0.26 & 0.28 & 0.18 & 0.22 & 0.16 & 0.17 \\
\hline Father's years of residence: $0-7$ & 0.04 & 0.04 & 0 & 0 & 0 & 0 \\
\hline Father's years of residence: 8-14 & 0.11 & 0.1 & 0 & 0 & 0 & 0 \\
\hline Father's years of residence: $\geq 15$ & 0.14 & 0.13 & 0 & 0 & 0 & 0 \\
\hline Father unemployed & 0.05 & 0.04 & 0.06 & 0.04 & 0.04 & 0.04 \\
\hline Father employed & 0.95 & 0.96 & 0.94 & 0.96 & 0.96 & 0.96 \\
\hline Father's education: degree & 0.14 & 0.14 & 0.11 & 0.13 & 0.13 & 0.14 \\
\hline Father's education: secondary school & 0.48 & 0.5 & 0.47 & 0.47 & 0.45 & 0.47 \\
\hline Father's education: primary school & 0.38 & 0.35 & 0.43 & 0.4 & 0.42 & 0.39 \\
\hline Accommodation: rented & 0.42 & 0.35 & 0.2 & 0.18 & 0.19 & 0.15 \\
\hline Accommodation: owned & 0.47 & 0.6 & 0.68 & 0.76 & 0.71 & 0.78 \\
\hline Accommodation: other title & 0.1 & 0.06 & 0.12 & 0.07 & 0.1 & 0.07 \\
\hline Number of rooms $\leq 2$ & 0.29 & 0.28 & 0.17 & 0.17 & 0.18 & 0.17 \\
\hline Number of rooms $>2$ & 0.7 & 0.72 & 0.83 & 0.83 & 0.82 & 0.83 \\
\hline Observations & 1000 & 1344 & 2153 & 2036 & 45940 & 44638 \\
\hline
\end{tabular}




\subsection{Empirical strategy}

We use the propensity score matching estimator (PSM) of Imbens (2000) and Lechner (2002) in a DD model, to estimate the short-term impact of the Italian immigration law on the probability of LBW. The use of PSDD estimators has become standard practice in the evaluation literature for the case of single treatment, although extensions to multiple treatments have recently been proposed (e.g., Moreno-Serra (2008)). The main advantage of this approach is the possibility of accounting, among treatment and control groups, for differences in initial conditions or other time invariant unobservable characteristics with the DD strategy, and to eliminate the bias induced by differences in observable characteristics with the PSM approach.

We formalize our empirical framework starting from the classical DD model, expressed as follows:

$$
Y_{i t}=\gamma_{0}+\gamma_{1} T_{i}+\gamma_{2} \text { Time }_{t}+\gamma_{3}(T \times \text { Time })_{i t}+\sum_{h=1}^{H} \psi_{h} X_{i t h}+\epsilon_{i t}
$$

where $Y_{i t}$ is a binary indicator with value 1 if the birth weight of newborn $i$ at time $t$ is below $2500 \mathrm{gr}$ and 0 otherwise. $T_{i}$ is a dummy variable indicating treatment status for each individual $i$. We define immigrant mothers as treated, whereas the two control groups are composed of foreign-born mothers with acquired Italian nationality and Italian mothers, respectively. Time $_{t}$ is a time dummy variable which indicates data collected during wave $_{1}$ or wave $_{2}$. The coefficient associated with $T_{i}, \gamma_{1}$, captures any pre-existing difference among treatment and control groups; the coefficient associated with Time $_{t}, \gamma_{2}$, is a proxy for unobserved variables which may affect treatment and control group birth weight outcomes not associated with the immigration law. The effect of regularization is captured by $\gamma_{3}$, estimated as the interaction between $T_{i}$ and Time $_{t}$.

Combination with the PSM estimator ensures that all individuals in the treatment group are compared with their counterparts in the comparison group, who are similar according to observable characteristics. Blundell \& Dias (2000) show that the combined PSDD estimate of $\gamma_{3}$ is given by the following equation:

$$
\hat{\gamma}_{3, P S D D}=\frac{1}{N_{T_{a}}} \sum_{i \in T_{a} \cap S}\left[\left(Y_{i}^{T_{a}}-\sum_{i \in C_{a} \cap S} W_{i j} Y_{j}^{C_{a}}\right)-\left(\sum_{j \in T_{b} \cap S} W_{i j} Y_{j}^{T_{b}}-\sum_{j \in C_{b} \cap S} W_{i j} Y_{j}^{C_{b}}\right)\right]
$$


where $T_{a}$ and $C_{a}$ represent the treatment and control groups after regularization. $T_{b}$ and $C_{b}$ represent the same groups before the immigration law came into force. $S$ is joint common support, defined as the subset of treated individuals who are matched for the construction of each counterfactual group. $N_{T_{a}}$ represents the number of treated individuals who also belong to the joint common support $S . Y$, as before, is the low birth weight indicator, and $W_{i j}$ is the weight attributed to matched individual $j$ when compared with treated individual $i$. From the empirical point of view, matching on covariates $X$ must be performed three times for each treated individual: the first time between $T_{a}$ and $T_{b}$ to find comparable treated individuals in the period before the law came into force, the second time between $T_{a}$ and $C_{a}$ and between $T_{a}$ and $C_{b}$, to find comparable individuals in the comparison group before and after implementation of the law, respectively.

Lastly, in order to obtain consistent standard errors for the parameters of our DD models, we use a two-step estimator proposed by Donald \& Lang (2007), which produces efficient two-step estimation and t-statistics with approximately a t-distribution when the number of observations in each group is large.

\section{Results}

\subsection{Preliminary evidence}

In this section, we present descriptive evidence of immigrant women's fertility choices and the results of balancing tests after the PSM on observable covariates. Table 3 lists the percentages of immigrant and Italian mothers who had babies. The share of immigrant mothers, about $6-7 \%$ of the sample, does not vary substantially between the two waves. Table 4 also shows the percentages of immigrant women, with or without Italian nationality in each wave, and indicates whether fertility decisions varied after implementation of the law. We find evidence of an increase in the percentage of immigrant mothers - our treatment group - who decided to have a child (6-8 \% points) after the immigration law came into force. As the percentage of immigrant women did not vary between waves, it is reasonable to conclude that the increase in the number of newborns of immigrant mothers was spurred by the prospect of a reduction in socio-economic vulnerability induced by the 2002 regularization.

Panel (a) of Table 5 lists the results of the matching strategies. We compare covariates 
Table 3: Percentage of immigrant and Italian mothers

\begin{tabular}{lccc}
\hline \hline Year & Obs. & \% of Italian mothers & \% of immigrant mothers \\
\hline 2002 & 48715 & 0.94 & 0.06 \\
2005 & 48215 & 0.93 & 0.07 \\
\hline \hline \multicolumn{3}{c}{ Source: Birth Sample Surveys; wave $_{1}=$ year 2002 and wave $_{2}=$ year 2005; our estimates }
\end{tabular}

Table 4: Percentage of immigrant mothers with or without Italian nationality

\begin{tabular}{lccc}
\hline \hline Year & $\begin{array}{c}\text { Number of } \\
\text { observations }\end{array}$ & $\begin{array}{c}\text { Immigrant mothers } \\
\text { with Italian nationality (\%) }\end{array}$ & $\begin{array}{c}\text { Immigrant } \\
\text { mothers(\%) }\end{array}$ \\
\hline 2002 & 3124 & 0.686 & 0.313 \\
2005 & 3384 & 0.604 & 0.396 \\
\hline \hline \multicolumn{2}{r}{ Source: Birth Sample Surveys; wave $_{1}=$ year 2002 and wave $_{2}=$ year 2005; our estimates }
\end{tabular}

distributions between treatment and control groups before and after matching, using the variables already described in the previous section and listed in Table 2. We compute the median and mean of the absolute standardized bias and the pseudo $R$ - squared index, using nearest-neighbor, radius and kernel matching methods. Irrespective of matching strategy and control group, median and mean bias is reduced drastically, meaning that differences among treatment and control groups in observable characteristics decrease significantly after matching. Again, Table 5 shows that pseudo $R$-squared fell to almost zero after matching (from a value of 0.14 before matching). Yet, we find similar results when we compare our treatment group with the control group composed of Italian mothers (panel (b) of Table 5).

The right part of Table 5 lists the number of observations in treated and comparison groups before and after each matching. We note how, in the case of kernel and radius matching, a small number of observations is discarded after matching, whereas a relatively larger number is lost with the nearest-neighbor method (in order to obtain the required counterfactuals, about 10,000 observations over more than 90,000 were used when Italian mother are used as control group). This difference is explained by the fact that the nearest-neighbor strategy uses only those observations which represent the best matches for treated individuals, whereas the kernel and radius methods, using a wider set of observations, may be affected by higher levels of bias (Caliendo \& Kopeinig 2005). In order to perform a sensitivity analysis, the next section presents the estimates of the effect of regularization on LBW, with the counterfactual samples obtained from all three 
matching strategies.

Table 5: Tests for balancing of covariates, before and after matching

\begin{tabular}{|c|c|c|c|c|c|c|c|c|c|c|c|c|}
\hline \multirow[t]{2}{*}{$\begin{array}{l}\text { Matching } \\
\text { Method }\end{array}$} & \multicolumn{4}{|c|}{ Absolute standardized bias } & \multicolumn{2}{|c|}{ Pseudo R-squared } & \multicolumn{3}{|c|}{$\begin{array}{l}\text { Treated group } \\
\text { Observations }\end{array}$} & \multicolumn{3}{|c|}{$\begin{array}{c}\text { Comparison group } \\
\text { Observations }\end{array}$} \\
\hline & Before & After & Before & After & Before & After & Before & After & Lost & Before & After & Lost \\
\hline \multicolumn{13}{|c|}{ (a) Control group: immigrant mothers with Italian nationality } \\
\hline $\bar{N}$ & 13.27 & 2 & 11.03 & 1.7 & 0.14 & 0.00 & 1344 & 1266 & 78 & 5189 & 3750 & 1439 \\
\hline$R$ & 13.27 & 2.17 & 11.03 & 1.67 & 0.14 & 0.00 & 1344 & 1266 & 78 & 5189 & 5028 & 161 \\
\hline$K$ & 13.27 & 1.8 & 11.03 & 1.6 & 0.14 & 0.00 & 1344 & 1266 & 78 & 5189 & 5028 & 161 \\
\hline \multicolumn{13}{|c|}{ (b) Control group: Italian mothers } \\
\hline $\bar{N}$ & 14.43 & 3.57 & 10.27 & 3.47 & 0.17 & 0.01 & 1344 & 1274 & 70 & 91578 & 8593 & 82985 \\
\hline$R$ & 14.43 & 4.7 & 10.27 & 2.73 & 0.17 & 0.02 & 1344 & 1274 & 70 & 91578 & 90098 & 1480 \\
\hline K & 14.43 & 3.3 & 10.27 & 1.83 & 0.17 & 0.01 & 1344 & 1274 & 70 & 91578 & 90098 & 1480 \\
\hline
\end{tabular}

Note: Matching methods, $N=$ Nearest-neighbor; $R=$ Radius; $K=$ Kernel

Table 6 shows unconditional estimates of LBW variations and the average treatment effect on the treated (ATT) for treatment and control groups, before and after matching. As we can see, before matching immigrant mothers LBW decreases by 1.3 percentage points after regularization (from 2002 to 2005). Instead, LBW does not change for immigrant mothers with acquired Italian nationality. Consequently, the estimate of the unconditional ATT is -1.3 percentage points. Using the nearest-neighbor method to match treatment and control groups, we find that the absolute variation for treated individuals is reduced by 1.9 percentage points between years 2002 and 2005. Since LBW moderately increases for immigrant mothers with acquired Italian nationality ( 0.4 percentage points), the estimated ATT in this case is -2.3 percentage points. Note that ATTs obtained with radius and kernel matching are respectively -1.1 and -1.6 percentage points. Similar results hold when Italian mothers are used as comparison group.

\subsection{Main estimates}

Table 7 shows the estimates of the effect of immigrants' regularization, followed by the introduction of the Italian immigration law in 2002, on LBW obtained with immigrant mothers with acquired Italian nationality as control group. The left part of the table shows standard DD estimates of ATT, with the corresponding number of observations; the right part lists PSDD estimates of ATT obtained from three matching strategies, nearestneighbor, radius and kernel ${ }^{5}$. Although DD estimates show a slight reduction of LBW

\footnotetext{
${ }^{5} \mathrm{DD}$ estimates were obtained by including the same control variables used for matching.
} 
Table 6: Low birth weight absolute variations and ATT (2002-2005), before and after matching

\begin{tabular}{|c|c|c|c|c|c|}
\hline \multirow[t]{2}{*}{ Panel $a$} & \multicolumn{5}{|c|}{ Control group: immigrant mothers with acquired Italian nationality } \\
\hline & & 2002 & 2005 & Absolute variation & ATT \\
\hline & \multicolumn{5}{|c|}{ Before matching } \\
\hline Treated group & & 0.072 & 0.059 & -0.013 & -0.013 \\
\hline \multirow[t]{2}{*}{ Comparison group } & & 0.054 & 0.054 & 0 & \\
\hline & \multicolumn{5}{|c|}{ After matching } \\
\hline Treated group & $N$ & 0.076 & 0.057 & -0.019 & -0.023 \\
\hline Comparison group & & 0.052 & 0.056 & 0.004 & \\
\hline Treated group & $R$ & 0.072 & 0.061 & -0.011 & -0.011 \\
\hline Comparison group & & 0.059 & 0.059 & 0.000 & \\
\hline Treated group & $K$ & 0.074 & 0.062 & -0.012 & -0.016 \\
\hline Comparison group & & 0.055 & 0.059 & 0.004 & \\
\hline \multirow[t]{2}{*}{ Panel b } & \multicolumn{5}{|c|}{ Control group: Italian mothers } \\
\hline & \multicolumn{5}{|c|}{ Before matching } \\
\hline Treated group & & 0.072 & 0.059 & -0.013 & -0.017 \\
\hline \multirow[t]{2}{*}{ Comparison group } & & 0.051 & 0.055 & 0.004 & \\
\hline & \multicolumn{5}{|c|}{ After matching } \\
\hline Treated group & $N$ & 0.075 & 0.058 & -0.017 & -0.022 \\
\hline Comparison group & & 0.052 & 0.057 & 0.005 & \\
\hline Treated group & $R$ & 0.071 & 0.062 & -0.009 & -0.012 \\
\hline Comparison group & & 0.053 & 0.056 & 0.003 & \\
\hline Treated group & $K$ & 0.073 & 0.059 & -0.014 & -0.018 \\
\hline Comparison group & & 0.053 & 0.057 & 0.004 & \\
\hline
\end{tabular}

Note: Matching methods, $N=$ Nearest-neighbor; $R=$ Radius; $K=$ Kernel

probability after regularization, the estimated coefficient is not statistically significant at the 95 percent confidence level $(-0.0065 ;$ s.e. $=0.013)$. Instead, PSDD estimates show a significant reduction in terms of LBW in the treatment group after regularization. The estimated marginal effects vary from -0.017 (s.e. $=0.010)$ to -0.0264 (s.e. $=0.014$ ). Note that, although the effect estimated after nearest-neighbor matching seems larger than the others, it is not statistically different from those obtained from other methods. This evidence allows us to conclude that the choice of matching procedure does not affect our results.

When we use Italian mothers as control group (Table 8), we confirm the previous estimates. Again, we find no significant effects of the regularization on LBW when we use the DD estimator $(-0.0123$; s.e.=0.010), whereas ATTs obtained from the PSDD estimator are significant and negative. Consistent with the differences shown in Table 7, the effects estimated in this case are similar to those obtained above and, according to matching 
method, range between -0.0185 (s.e. $=0.011$ ) and $-0.0278($ s.e. $=0.014$ ) after kernel and nearest-neighbor matching respectively, whereas after radius matching the estimated effect is not significant.

These results strengthen our conclusion about the positive causal impact of immigrants regularization on LBW. Although the socio-economic vulnerability of immigrant mothers is partly responsible for the negative health outcomes of newborns in universal health systems like the Italian one, we find that being regularized reduces LBW by about 1.2-2.7 percentage points. Job regularization, ensuring that new regular migrants are completely entitled to and provided with equitable access to prenatal health care, influence fertility choices and improve newborns' health outcomes.

Table 7: Effect of immigration law on birth weight inequalities of immigrant women, marginal effects (control group: immigrant mothers with acquired Italian nationality)

\begin{tabular}{lllcc}
\hline \hline & DD & & PSDD & \\
\hline ATT & Observations & Matching method & ATT & Observations \\
\hline-0.0065 & 6303 & Nearest-neighbor & $-0.0264^{*}$ & 5016 \\
$(0.009)$ & & $(0.014)$ & \\
& & $-0.0117^{*}$ & 6294 \\
& & $(0.007)$ & \\
& & $-0.0167^{*}$ & 6294 \\
& Kadius & $(0.010)$ & \\
\hline \hline
\end{tabular}

Notes: Standard errors in parentheses obtained with two-step procedure proposed by Donald E Lang (2007). Significant levels: p-value $* * * \leq 0.01, * * \leq 0.05, * \leq 0.1$.

Table 8: Effect of immigration law on birth weight inequalities of immigrant women, marginal effects (control group: Italian mothers)

\begin{tabular}{lllcc}
\hline \hline \multicolumn{1}{c}{ DD } & & PSDD & \\
\hline ATT & Observations & Matching method & ATT & Observations \\
\hline-0.0123 & 91373 & Nearest-neighbor & $-0.0278^{* *}$ & 9867 \\
$(0.010)$ & & $(0.014)$ & \\
& & -0.0134 & 91372 \\
& & $(0.010)$ & \\
& & $-0.185^{*}$ & 91372 \\
& \multirow{2}{*}{ Kadius } & $(0.011)$ & \\
\hline \hline
\end{tabular}

Notes: Standard errors in parentheses obtained with two-step procedure proposed by Donald ES Lang (2007). Significant levels: p-value ${ }^{* * *} \leq 0.01, * * \leq 0.05, * \leq 0.1$. 


\subsection{Robustness checks}

In this section, we test for distorting effects due to the presence in our baseline sample of mothers non-eligible for regularization. In order to address this question, we identify two population subgroups, which we know were affected by immigration regularization to different extents.

The first subgroup compares birth weight variations for newborns with father in employment $\left(\right.$ subgroup $\left._{1}\right)$. The second group is defined as newborns with mother or father in employment $\left(\right.$ subgroup $\left._{2}\right)$. In particular, the latter subgroup is used to evaluate whether the combined effect of regularization on both parents is more effective on LBW reductions. In this group, treated mothers are presumed to be affected directly, because eligibility for regularization is connected with employment status. To keep our estimates consistent, we need to verify whether currently employed mothers were in the same status also during pregnancy, otherwise we may have in our subgroup mothers who found a job after pregnancy, but who were non-eligible for regularization in 2002. To verify this condition, we recovered information from a restricted sample of the BSS on how many mothers were employed during pregnancy and whether they changed employment status after pregnancy. About $50 \%$ of immigrant mothers were employed during pregnancy; the remaining $50 \%$ were housewives. Among those in employment, $90 \%$ was still in employment at the moment of the interview (2005). For the remaining $50 \%$ of housewives, they may have been affected by regularization indirectly, if their husband or partner was eligible for regularization.

The DD model, shown in equation (1), can be extended to estimate the effects of regularization on various subgroups of the population. For instance:

$$
Y_{i t}=\gamma_{0}+\gamma_{1} T_{i}^{k}+\gamma_{2} \text { Time }_{t}+\gamma_{3}\left(T^{k} \times \text { Time }\right)_{i t}+\sum_{h=1}^{H} \psi_{h} X_{i t h}+\epsilon_{i t}
$$

where superscript $K=1,2$ corresponds to the already described subgroups. Consequently, PSDD estimates are obtained from:

$$
\hat{\gamma}_{3, P S D D}^{k}=\frac{1}{N_{T_{a}^{k}}} \sum_{i \in\left(T_{a}^{k} \cap S\right)}\left[\left(Y_{i}^{T_{a}^{k}}-\sum_{i \in\left(C_{a}^{k} \cap S\right)} W_{i j} Y_{j}^{C_{a}^{k}}\right)-\left(\sum_{j \in\left(T_{b}^{k} \cap S\right)} W_{i j} Y_{j}^{T_{b}^{k}}-\sum_{j \in\left(C_{b}^{k} \cap S\right)} W_{i j} Y_{j}^{C_{b}^{k}}\right)\right] .
$$

The results of matching procedures are shown in Appendix A and are similar to those 
of the whole sample. Also in this case, the PSM obtained with the same methods as before (nearest-neighbor, kernel and radius) performs well in reducing bias from observable covariates. Table 9 shows the results of the estimated effects of the 2002 regularization on the above subgroups. First, DD estimates of the ATT are not significant in the subgroups analysed. Second, focusing on the PSDD estimator, ATTs are always significant and point estimates are close to those obtained from the whole sample. In this case, regularization reduces the probability of LBW by about 1.2-2.5 percentage points. Third, as Table 10 shows, estimates for subgroups are still very similar to those described above, even when we consider Italian mothers as control group.

Table 9: Effect of immigration law on birth weight inequalities of immigrant women, marginal effects (control group: immigrant mothers with acquired Italian nationality)

\begin{tabular}{|c|c|c|c|c|c|}
\hline & \multicolumn{2}{|c|}{ DD } & \multicolumn{3}{|c|}{ PSDD } \\
\hline & ATT & Observations & Matching method & ATT & Observations \\
\hline \multirow[t]{4}{*}{ Subgroup $_{1}$} & -0.0085 & 2555 & Nearest-neighbor & $-0.0196^{*}$ & 4776 \\
\hline & $(0.008)$ & & & $(0.011)$ & \\
\hline & & & Radius & $\begin{array}{c}-0.0121^{*} \\
(0.007)\end{array}$ & 6006 \\
\hline & & & Kernel & $\begin{array}{c}-0.0200^{* *} \\
(0.010)\end{array}$ & 6006 \\
\hline \multirow[t]{3}{*}{ Subgroup $_{2}$} & $\begin{array}{c}-0.0073 \\
(0.008)\end{array}$ & 6012 & Nearest-neighbor & $\begin{array}{c}-0.0248^{* *} \\
(0.011)\end{array}$ & 4861 \\
\hline & & & Radius & $\begin{array}{c}-0.0117^{*} \\
(0.007)\end{array}$ & 6113 \\
\hline & & & Kernel & $\begin{array}{c}-0.0183^{*} \\
(0.010)\end{array}$ & 6113 \\
\hline
\end{tabular}

Notes: Standard errors in parentheses obtained with two-step procedure proposed by Donald 83 Lang (2007). Significant levels: p-value $* * * \leq 0.01, * * \leq 0.05, * \leq 0.1$. 
Table 10: Effect of immigration law on birth weight inequalities of immigrant women, marginal effects (control group: Italian mothers)

\begin{tabular}{|c|c|c|c|c|c|}
\hline & \multicolumn{2}{|c|}{ DD } & \multicolumn{3}{|c|}{ PSDD } \\
\hline & ATT & Observations & Matching method & ATT & Observations \\
\hline \multirow[t]{3}{*}{ Subgroup $_{1}$} & $\begin{array}{l}-0.0136 \\
(0.011)\end{array}$ & 50168 & Nearest-neighbor & $\begin{array}{c}-0.0217^{*} \\
(0.011)\end{array}$ & 9434 \\
\hline & & & Radius & $\begin{array}{c}-0.0145 \\
(0.012)\end{array}$ & 87747 \\
\hline & & & Kernel & $\begin{array}{c}-0.0221^{*} \\
(0.013)\end{array}$ & 87747 \\
\hline \multirow[t]{3}{*}{ Subgroup $_{2}$} & $\begin{array}{c}-0.0125 \\
(0.010)\end{array}$ & 87749 & Nearest-neighbor & $\begin{array}{c}-0.0259^{*} \\
(0.014)\end{array}$ & 9710 \\
\hline & & & Radius & $\begin{array}{l}-0.0143 \\
(0.011)\end{array}$ & 88051 \\
\hline & & & Kernel & $\begin{array}{c}-0.0221^{*} \\
(0.013)\end{array}$ & 88051 \\
\hline
\end{tabular}

Notes: Standard errors in parentheses obtained with two-step procedure proposed by Donald 69 Lang (2007). Significant levels: p-value $* * * 0.01, * * \leq 0.05, * \leq 0.1$. 


\section{Conclusions}

This study examines the application of a regularization norm proposed within the 189/2002 Italian immigration law, addressed to regularize immigrants working in domestic services, as carers and in industry, and investigates its effects on the health outcomes of newborns. Unexploited official datasets on babies born in Italy, before and after the immigration law, allowed us to estimate with a quasi-experimental setting the impact on LBW of the massive regularization.

We used a PSDD estimator, which combines a PSM approach within a DD model, to account for observable and unobservable differences among treatment and control groups. We assumed that the exogenous variation in immigration regularization implied an improvement in immigrants' economic and social security and fostered their fertility choices. Irrespective of control group adopted, we found that overall LBW decreased significantly, irrespective of the matching method used, with an estimated reduction that ranges from 1.2 to 2.7 percentage points.

We also performed a robustness check to test whether the causal effect estimated from the entire sample was biased by the presence of immigrant mothers who were not directly affected by regularization. We defined two subgroups in which at least one parent was eligible for regularization. Results show that also in this case the estimated effect of regularization on LBW from the basic DD model were not significant. PSDD point estimates were found to be very similar to those obtained from the whole sample.

Our findings indicate that immigration policies which favor socio-economic integration of immigrants are effective in reducing the health disparities of newborns. More importantly, our analysis shows that the channel of transmission of the benefits occurs by means of family integration, irrespective of whether mother or father were regularized.

Lastly, since the majority of immigrants who received permits to stay in 2002 remained in Italy in the long term, and since health status at birth is related to better cognitive abilities throughout the life-cycle, our study indicates that immigration regularization may also have implications in terms of future productivity. For these reasons, we believe that our results are important for the design of future immigration policies. 


\section{References}

Abrevaya, J. \& Dahl, C. (2008), 'The effects of birth inputs on birthweight', Journal of Business \& Economic Statistics 26, 379-397.

Almond, D., K.Y., C. \& D.S., L. (2005), 'The costs of low birth weight', The Quarterly Journal of Economics 120(3), 1031-1083.

Amuedo-Dorantes, C. \& Mundra, K. (2005), 'Impact of Immigration on Prenatal Care Use and Birth Weight: Evidence from California in the 1990's', The American Economic Review 93(2), 1177-1205.

Bacci, S., Bartolucci, F. \& Pieroni, L. (2012), 'A causal analysis of mother's education on birth inequalities', MPRA Paper 38754 .

Bertrand, M., Duflo, E. \& Mullainathan, S. (2004), 'How much should we trust differencesin-differences estimates?', The Quarterly Journal of Economics 119(1), 249-275.

Blundell, R. \& Dias, M. C. (2000), 'Evaluation methods for non-experimental data', Fiscal Studies 21(4), 427-468.

Bonifazi, C., Heins, F., Strozza, S. \& Vitiello, M. (2009), 'The Italian transition from emigration to immigration country', IRPPS WPs (24).

Borjas, G. J. (1990), 'Self-selection and the earnings of immigrants: Reply', American Economic Review 80(1), 305-08.

Caliendo, M. \& Kopeinig, S. (2005), Some practical guidance for the implementation of propensity score matching, IZA Discussion Papers 1588, Institute for the Study of Labor (IZA).

Carfagna, S., Gabrielli, D., Sorvillo, M. \& Strozza, S. (2008), 'Changes of status of immigrants in italy: results of a record-linkage on administrative sources', European Population Conference, Barcelona .

Chiavarini, M., Bartolucci, F., Gili, A., Pieroni, L. \& Minelli, L. (2012), 'Effects of individual and social factors on preterm birth and low birth weight: empirical evidence from regional data in Italy', International Journal of Public Health 57, 261-268. 
Donald, S. G. \& Lang, K. (2007), 'Inference with difference-in-differences and other panel data', The Review of Economics and Statistics 89(2), 221-233.

Geraci, S., Bonciani, M. \& Martinelli, B. (2010), La tutela della salute degli immigrati nelle politiche locali, Technical report, ROMA: Inprinting srl.

Heckman, J. (2000), 'Policies to foster human capital.', Research in Economics 54(1), 356.

Hildebrandt, N. \& McKenzie, D. (2005), 'The effects of migration on child health in Mexico', ECONOMIA (257-289).

Imbens, G. (2000), 'The role of the propensity score in estimating dose-response functions', Biometrika (87), 706-710.

ISTAT (2001), Rilevazione degli iscritti in anagrafe per nascita, Technical report, ROMA: Inprinting srl.

ISTAT (2002), Rilevazione degli iscritti in anagrafe per nascita, Technical report, ROMA: Inprinting srl.

ISTAT (2003), Rilevazione degli iscritti in anagrafe per nascita, Technical report, ROMA: Inprinting srl.

Lechner, M. (2002), 'Program heterogeneity and propensity score matching: An application to the evaluation of active labor market policies', The Review of Economics and Statistics 84(2), 205-220.

Moreno-Serra, R. (2008), Health Programme Evaluation by Propensity Score Matching: Accounting for Treatment Intensity and Health Externalities with an Application to Brazil, Technical report.

Urquia, M., Glazier, R., Blondel, B. \& et al. (2010), 'International migration and adverse birth outcomes: role of ethnicity, region of origin and destination', J Epidemiol Community Health 64, 243251. 


\section{APPENDIX A}

Table A.1: Tests for balancing of covariates, before and after matching, with control group of immigrant mothers with Italian nationality

\begin{tabular}{|c|c|c|c|c|c|c|c|c|c|c|c|c|c|}
\hline & & \multicolumn{4}{|c|}{ Absolute standardized bias } & \multirow{2}{*}{\multicolumn{2}{|c|}{ Pseudo R-squared }} & \multirow{2}{*}{\multicolumn{3}{|c|}{$\begin{array}{c}\text { Treated group } \\
\text { Observations }\end{array}$}} & \multirow{2}{*}{\multicolumn{3}{|c|}{$\begin{array}{c}\text { Comparison group } \\
\text { Observation }\end{array}$}} \\
\hline & & \multicolumn{2}{|c|}{ Median } & \multicolumn{2}{|c|}{ Mean } & & & & & & & & \\
\hline & & Before & After & Before & After & Before & After & Before & After & Lost & Before & After & Lost \\
\hline \multicolumn{14}{|c|}{ (a) Control group: immigrant mothers with Italian nationality } \\
\hline \multirow[t]{2}{*}{$\overline{N N}$} & Subgroup $_{1}$ & 14.1 & 2.13 & 11.57 & 1.8 & 0.15 & 0.00 & 1275 & 1214 & 61 & 4912 & 3562 & 1350 \\
\hline & Subgroup $_{2}$ & 13.83 & 2.03 & 11.43 & 1.8 & 0.15 & 0.00 & 1313 & 1236 & 77 & 5016 & 3562 & 1350 \\
\hline \multirow[t]{2}{*}{$R$} & Subgroup $_{1}$ & 14.1 & 2.27 & 11.57 & 1.83 & 0.15 & 0.00 & 1275 & 1214 & 61 & 4912 & 4792 & 120 \\
\hline & Subgroup $_{2}$ & 13.83 & 2.33 & 11.43 & 1.77 & 0.15 & 0.00 & 1313 & 1236 & 77 & 5016 & 4877 & 139 \\
\hline \multirow[t]{2}{*}{ K } & Subgroup $_{1}$ & 14.1 & 1.93 & 11.57 & 1.53 & 0.15 & 0.00 & 1275 & 1214 & 61 & 4912 & 4792 & 120 \\
\hline & Subgroup $_{2}$ & 13.83 & 1.9 & 11.43 & 1.37 & 0.15 & 0.00 & 1313 & 1236 & 77 & 5016 & 4877 & 139 \\
\hline \multicolumn{14}{|c|}{ (a) Control group: Italian mothers } \\
\hline \multirow[t]{2}{*}{$N N$} & Subgroup $_{1}$ & 15.27 & 3.6 & 11.03 & 3.47 & 0.17 & 0.01 & 1275 & 1218 & 57 & 87257 & 8216 & 79041 \\
\hline & Subgroup $_{2}$ & 15 & 3.77 & 11.23 & 3.67 & 0.17 & 0.01 & 1313 & 1247 & 66 & 88857 & 8463 & 80394 \\
\hline \multirow[t]{2}{*}{$R$} & Subgroup $_{1}$ & 15.27 & 4.97 & 11.03 & 2.87 & 0.17 & 0.02 & 1275 & 1218 & 57 & 87257 & 86529 & 728 \\
\hline & Subgroup $_{2}$ & 15 & 4.9 & 11.23 & 2.87 & 0.17 & 0.02 & 1313 & 1247 & 66 & 88857 & 86804 & 2053 \\
\hline \multirow[t]{2}{*}{ K } & Subgroup $_{1}$ & 15.27 & 3.43 & 11.03 & 2.17 & 0.17 & 0.01 & 1275 & 1218 & 57 & 87257 & 86529 & 728 \\
\hline & Subgroup $_{2}$ & 15 & 3.47 & 11.23 & 2.3 & 0.17 & 0.01 & 1313 & 1247 & 66 & 88857 & 86804 & 2053 \\
\hline
\end{tabular}

Note: Matching methods, $N=$ Nearest-neighbor; $R=$ Radius; $K=$ Kernel. Subgroup $p_{1}=$ employed father, Subgroup $_{2}=$ employed mother or father 